\title{
POFUT1 as a Promising Novel Biomarker of Colorectal Cancer
}

\author{
Julien Chabanais $^{1}\left(\mathbb{D}\right.$, François Labrousse ${ }^{2}$, Alain Chaunavel ${ }^{2} \mathbb{D}$, Agnès Germot ${ }^{1,+}(\mathbb{D})$ and \\ Abderrahman Maftah $1, *,+$ \\ 1 Glycosylation and Cell Differentiation, Limoges University, PEIRENE, EA 7500, \\ F-87060 Limoges cedex, France; julien.chabanais@unilim.fr (J.C.); agnes.germot@unilim.fr (A.G.) \\ 2 Department of Pathology, Limoges University Hospital, 87042 Limoges cedex, France; \\ francois.labrousse@unilim.fr (F.L.); alain.chaunavel@chu-limoges.fr (A.C.) \\ * Correspondence: abderrahman.maftah@unilim.fr \\ + Abderrahman Maftah and Agnès Germot are considered co-last authors and contributed equally to \\ this work.
}

Received: 19 September 2018; Accepted: 27 October 2018; Published: 30 October 2018

\begin{abstract}
Background: While protein O-fucosyltransferase 1 (POFUT1) overexpression has been recently proposed as a potential biomarker for different cancer types, no study was carried out on POFUT1 implication in colorectal cancer (CRC). Methods: Data from 626 tumors and 51 non-tumor adjacent tissues available in FireBrowse had been used in this study. Statistical analyses on POFUT1 expression and gene copy number, $\mathrm{NOTCH}$ receptors (main targets of POFUT1 enzymatic activity) expression and association of POFUT1 and NOTCH1 expressions with clinical parameters were investigated. Data were completed by POFUT1 histological labeling on six tumor tissues from patients with CRC. Results: We found that POFUT1 is overexpressed from the stage I $(p<0.001)$ and $76.02 \%$ of tumors have a 20q11.21 amplification, associated in $90.13 \%$ of cases with a POFUT1 overexpression, compared to non-tumor adjacent tissues. The POFUT1 copy number in tumors is mainly between 2 and 3. POFUT1 is positively correlated with NOTCH1 $\left(\mathrm{r}_{\mathrm{s}}=0.34, p<0.001\right)$, NOTCH3 $\left(\mathrm{r}_{\mathrm{s}}=0.087\right.$, $p=0.0297)$, and NOTCH4 $\left(\mathrm{r}_{\mathrm{s}}=0.097, p=0.0148\right)$ expressions, while negatively correlated with NOTCH2 expression $\left(\mathrm{r}_{\mathrm{s}}=-0.098, p=0.0142\right)$. POFUT1 overexpression is markedly associated with rectal location, non-mucinous adenocarcinoma and cancer stages IV and M1. NOTCH1 overexpression is only associated with rectal location and non-mucinous adenocarcinoma. Conclusion: We conclude that POFUT1 is overexpressed in CRC from stage I, and its high expression is associated with metastatic process, probably through NOTCH pathway activation. Then, POFUT1 could represent a potential novel biomarker for CRC diagnosis.
\end{abstract}

Keywords: POFUT1; colorectal cancer; early detection; biomarker; NOTCH

\section{Introduction}

Colorectal cancer (CRC) is the third most commonly diagnosed cancer in males and the second in females with 1.65 million new cases and almost 835,000 deaths in 2015 [1]. The majority of CRC (75\%) has a sporadic origin but in some cases the origin is related to familial heredity or due to inflammatory bowel diseases [2]. Although the mortality associated with CRC declined over the past decades, identification of new biomarkers for an early diagnosis and the improved treatment of CRC are crucial. Previous studies have demonstrated the association between glycosylation changes and tumorigenesis [3,4]. Glycosylation is the main post-translational modification of proteins. $N$ - and/or $O$-glycans play major roles as in protein conformation then modulating their functional activity [5], in ligand-receptor complex formation for cell-cell interactions [6], and in cellular metabolism [7]. Fucose 
is frequently found as a carbohydrate constituent of $N$-glycans at peripheral positions but also, linked to core $\mathrm{N}$-acetylglucosamine. It is involved in selectin-dependent leukocyte adhesion, maternal-fetal interface stability, and formation of Lewis blood group antigen [8-10]. In malignant transformation, fucosyltransferases are altered in their expressions and activities. For example, in CRC the $\alpha 1,6$ core-fucosyltransferase encoded by FUT8 is increased in both enzyme activity and protein expression during malignant transformation [11]. The $\alpha 1,3 / 4$-fucosyltransferase gene FUT6 is overexpressed in colorectal tissues where the enzyme functions as a tumor regulator by promoting cell growth, migration, invasion and angiogenesis [12]. $O$-fucosylation is an atypical post-translational modification of proteins catalyzed by two glycosyltransferases, Protein $O$-fucosyltransferase 1 (Pofut1) and Protein $O$-fucosyltransferase 2 (Pofut2). Pofut1 modifies epidermal growth factor-like (EGF-like) domains and Pofut2 modifies thrombospondin repeats (TSR) [13]. Increasing evidences demonstrate the role of Pofut in controlling the balance between non-differentiated and differentiated normal cells $[14,15]$. The human glycoprotein POFUT1 consists of 393 amino acids encoded by a gene located between PLAGL2 and KIF3B on the long arm of chromosome 20, near the centromere [16]. Pofut1 is an ER-resident enzyme [17], which allows fucose addition [18] on $S$ or $T$ included in the $C^{2} X_{4}(S / T) C^{3}$ consensus motif, where $C^{2}$ and $C^{3}$ are the second and third cysteines of the 6 conserved ones in EGF-like domains. The major known target of Pofut1 is Notch receptor, with four paralogs in human, NOTCH1 to NOTCH4, which contain between 29 and 36 EGF-like domains with 14 to $20 O$-fucosylation consensus sites [19]. Correct glycosylation of Notch receptors especially their $O$-fucosylation [20] is necessary for subsequent optimal cleavages releasing the NICD (Notch intracellular domain), which translocates into the nucleus to control transcription of target genes [21]. In mice, Pofut1 knockout is lethal; embryos die at midgestation with severe defects in somitogenesis, cardiogenesis, and neurogenesis, and their phenotype is similar to that of embryos lacking downstream effectors of NOTCH signaling pathway [22]. POFUT1 knockdown in HEK293T cells induces a 2-fold reduction of the amount of NOTCH1 on the cell surface [23]. Indeed, $O$-fucose addition contributes to EGF-like stabilization, which participates to a novel ER quality control pathway, essential to correct targeting of Notch to the cell membrane and its interaction with ligands [24]. Recent evidences demonstrated NOTCH implication in tumoral pathologies. In T cell acute lymphoblastic leukemia (T-ALL), NOTCH1 gene is mutated in at least $65 \%$ of the cases [25] and an aberrant $\mathrm{NOTCH}$ signaling is implicated in this pathologic development process [26]. An ectopic NOTCH1 expression triggers epithelial-mesenchymal transition in human breast cancer inducing tumor growth and metastasis [27]. In gastric cancer cells, NOTCH pathway activation also induces cell proliferation and metastasis, here through phosphorylated STAT3 and TWIST [28]. In CRC, NOTCH pathway participates to the tumor growth by promoting cell proliferation and inhibiting cell apoptosis [29]. As O-fucosylation of NOTCH receptor is necessary for its activation, several cancer studies focused on POFUT1 expression. A decade ago, the first finding showed a higher expression of POFUT1 in gliomas compared to normal cells [30]. More recently, POFUT1 overexpression was also detected in oral squamous cell carcinoma and correlated with an increase of tumor size [31]. In hepatocellular carcinomas, it was associated with a poor prognosis, as it induces an aberrant activation of NOTCH pathway, which promotes cell proliferation, migration and invasion [32]. In gastric cancer, increased POFUT1 expression is associated with some clinical features such as higher TNM staging and tumoral differentiation states [33]. POFUT1 gene is localized in the 20q11.21 region, which is frequently amplified in tumor cells as for breast [34] and gastric cancers [35], acute myeloid leukemia [36] and colorectal cancer with poor prognosis [37]. In this last case, a positive correlation is reported between POFUT1 expression and the copy number of the 20q11-13 amplicon [38]. All these data suggest that POFUT1 could play a significant role in cancer development.

Therefore, we started this study to evaluate POFUT1 expression in CRC and determine its potential value as a novel diagnostic biomarker for this cancer. Using Firebrowse database, we collected expression data from RNAseq, copy number variation (CNV) of POFUT1 gene and diverse clinical information. In parallel, based on six different colorectal tumors, we detected POFUT1 and estimated the number of POFUT1 copies. 


\section{Results}

\subsection{POFUT1 is Overexpressed in Human Colorectal Cancer Tissues}

On a panel of 28 cancer types available in FireBrowse database, POFUT1 expression is predominantly higher in 22 tumors compared to normal tissues (Figure 1A). COAD (colon adenocarcinoma) and READ (rectum adenocarcinoma) presented the greatest means of log2 RSEM (RNA-Seq by Expectation Maximization) 11.633 and 11.962, respectively for POFUT1, only being exceeded in chromophobe kidney carcinoma $\mathrm{KICH}$ (12.086). As expected, the COADREAD data, which are a compilation of COAD and READ, showed an increased POFUT1 expression in tumor compared to healthy tissues.

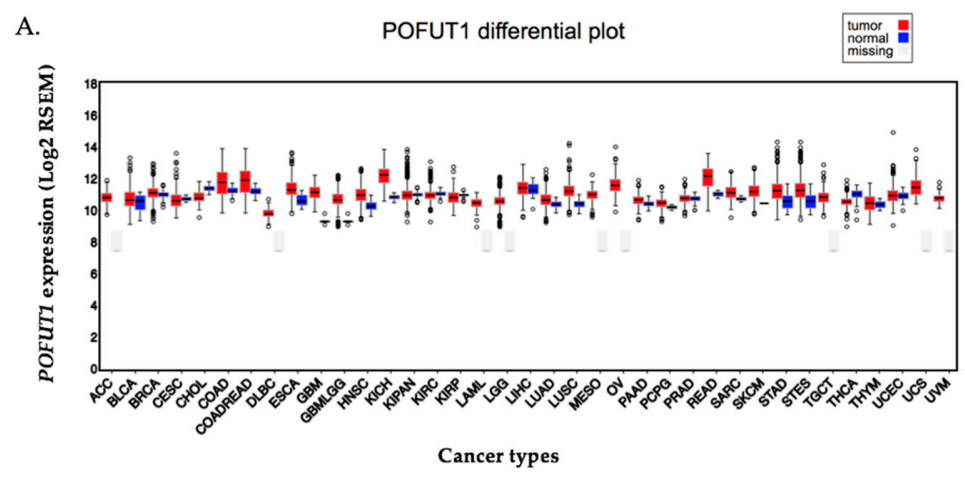

B.

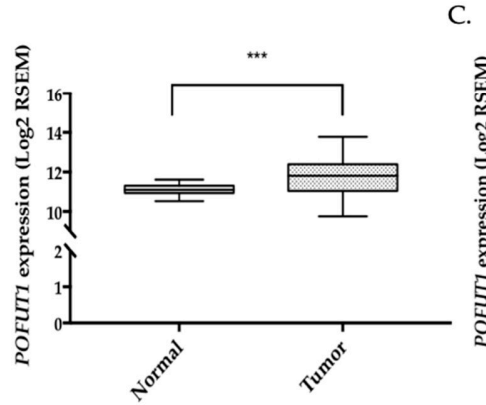

C.

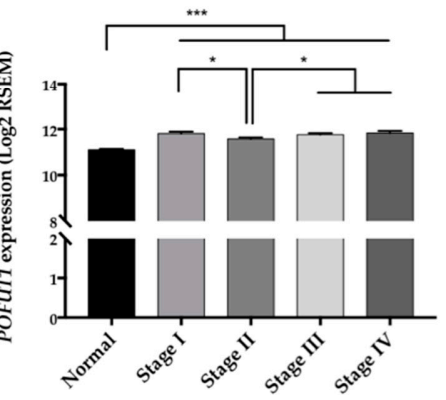

Figure 1. POFUT1 is overexpressed in most of cancer types especially in colorectal cancer from the first stage. RNAseq data from FireBrowse database show that in 22 cancer types (including COAD and READ), POFUT1 expression is higher than in the corresponding normal tissues and for 6 cancer types it is the reverse (A). Data are missing for nine cancer types. ACC: adrenocortical carcinoma, BLCA: bladder urothelial Carcinoma, BRCA: breast invasive carcinoma, CESC: cervical squamous cell carcinoma and endocervical adenocarcinoma, CHOL: cholangiocarcinoma, COAD: colon adenocarcinoma, COADREAD: colorectal adenocarcinoma, DLBC: lymphoid neoplasm diffuse large B-cell lymphoma, ESCA: esophageal carcinoma, GBM: glioblastoma multiforme, GBMLGG: glioma, HNSC: head and neck squamous cell carcinoma, KICH: kidney chromophobe, KIPAN: pan-kidney cohort, KIRC: kidney renal clear cell carcinoma, KIRP: kidney renal papillary cell carcinoma, LAML: acute myeloid leukemia, LGG: brain lower grade glioma, LIHC: liver hepatocellular carcinoma, LUAD: lung adenocarcinoma, LUSC: lung squamous cell carcinoma, MESO: mesothelioma, OV: ovarian serous cystadenocarcinoma, PAAD: pancreatic adenocarcinoma, PCPG: pheochromocytoma and paraganglioma, PRAD: prostate adenocarcinoma, READ: rectum adenocarcinoma, SARC: sarcoma, SKCM: skin Cutaneous Melanoma, STAD: stomach adenocarcinoma, STES: stomach and esophageal carcinoma, TGCT: testicular germ cell tumors, THCA: thyroid carcinoma, THYM: Thymoma, UCEC: uterine corpus endometrial carcinoma, UCS: uterine carcinosarcoma, UVM: uveal melanoma. COADREAD RNAseq data extracted from FireBrowse database containing $626 \mathrm{CRC}$ and 51 normal adjacent tissues show that POFUT1 is significantly overexpressed in tumor tissues (B) and from the first stage of tumor classification (C). For B. and C., bar graph represented mean of $\log 2$ RSEM \pm SEM. Statistical significance was assessed using a two-tailed Student test; ${ }^{*} p<0.05, * * * 0.001$. 
To investigate in detail POFUT1 expression in colorectal cancer (CRC), an in silico analysis using the RNAseq data of COADREAD samples extracted from FireBrowse was performed using 626 tumor and 51 adjacent non tumor tissues. POFUT1 expression is significantly higher in 459 (72.8\%) tumor compared to normal tissues $(p<0.001)$ (Figure 1B). The distinction between cancer stages showed a significant $(p<0.001)$ increase in POFUT1 expression whatever the stage is, therefore at the first signs of the tumor growth (Figure 1C). Stage II presented a lesser amount of POFUT1 transcripts compared to other stages. POFUT1 immunolabeling performed on tumors representing each CRC pathological stage confirms that POFUT1 is overexpressed in tumor (Figure 2A). To demonstrate anti-POFUT1 antibody (ab74302) specificity, we performed an immunofluorescence detection on two human colorectal cancer cell lines (HCT 116 and SW620) stably transfected or not, with shRNAs targeting POFUT1. As shown in Figure 2B, HCT 116 shPOFUT1 cell line, whose POFUT1 expression is 30\% lesser (quantification by Taqman probe qRT-PCR method), has a lower staining compared to HCT 116. This result is more accentuated with SW620 shPOFUT1 cell line, which has 60\% POFUT1 expression decrease compared to SW620. As the POFUT1 antibody (ab74302) was ineffective in immunoblotting, we used another antibody raised against Pofut1 and produced in our laboratory [39]. This antibody has been proven in different studies especially in mice [24,40]. Despite a low quality of protein migration due to the Optimal Cutting Temperature (OCT) embedded colorectal tissues, we observed an increase (1.134 and 1.565 fold) of POFUT1 labeling in tumor samples compared to normal tissues (Figure 2C). Such a result was confirmed on human colorectal cancer cell lines HCT 116, HT-29 and SW620 where the expression levels were respectively 2.680, 2.418 and 2.608 fold higher compared to the human embryonic colon cell line CCD841CoN (Figure 2D).

A.

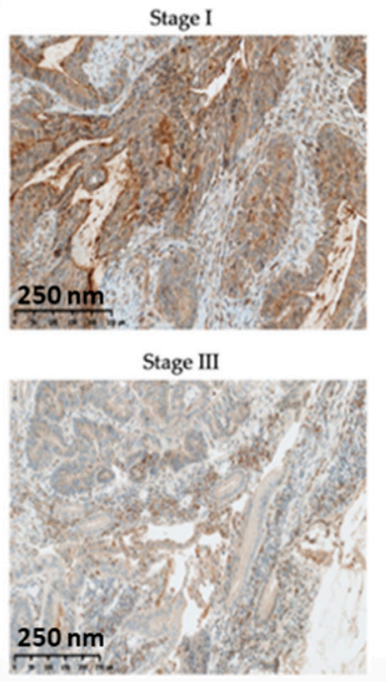

Stage II

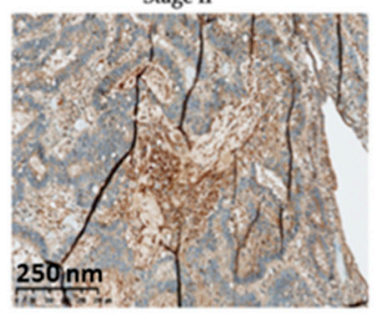

Stage IV

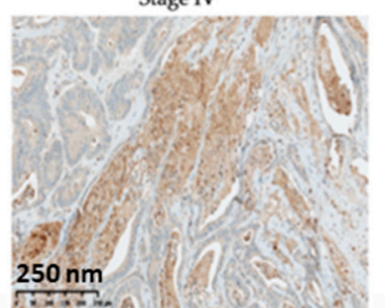

B.

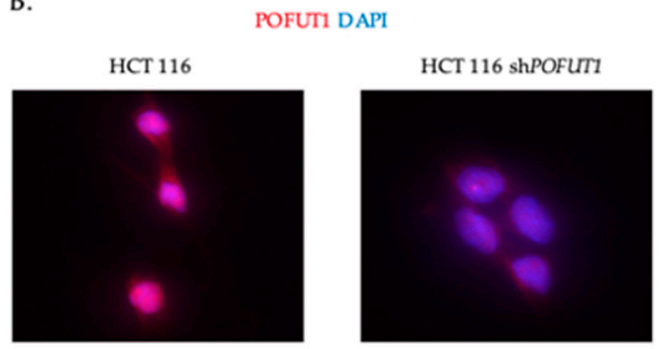

SW620

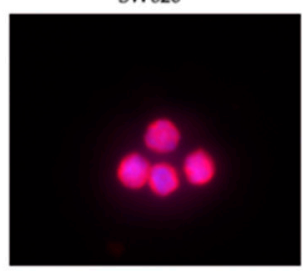

SW620 shPOFUT1

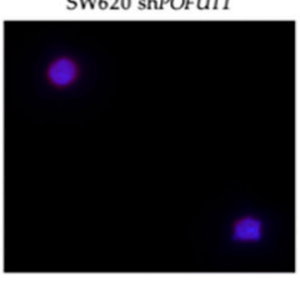

Figure 2. Cont. 


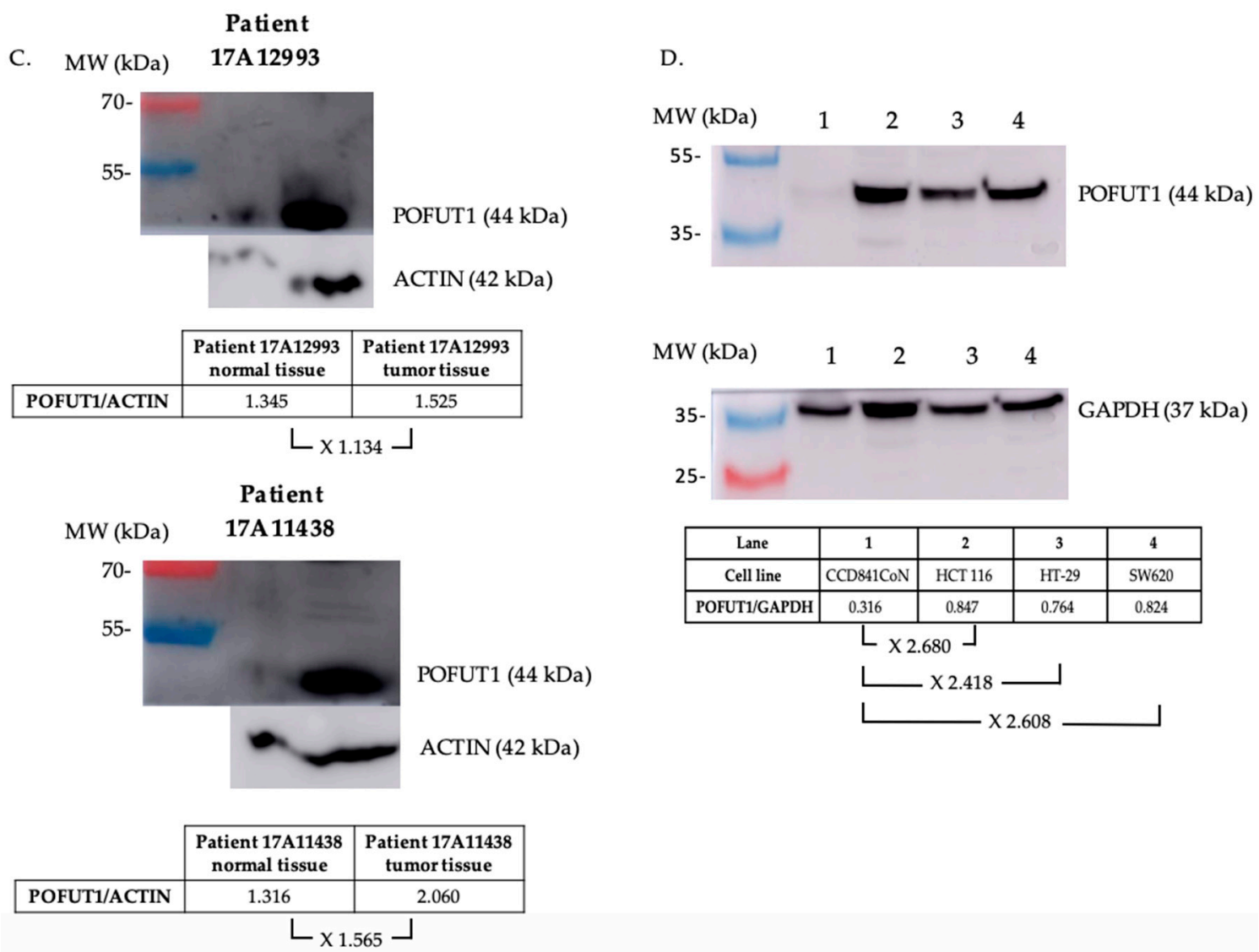

Figure 2. POFUT1 expression in colorectal tissues and cell lines. Immunohistochemistry analysis (A) shows that POFUT1 is overexpressed in tumor tissues from first colorectal cancer (CRC) stage. Immunofluorescence labeling of POFUT1 (red), performed on wild-type and POFUT1 knockdown HCT 116 and SW620 human colorectal cancer cell lines, confirmed the antibody specificity (B). Western blot realized on colorectal tissues (C) and colorectal CCD841CoN, HCT 116, HT-29 and SW620 cell lines (D) validate the POFUT1 overexpression in cancer samples compared to healthy samples.

\subsection{In CRC, 20q11.21 Chromosomic Region is Often Amplified, Which Induced POFUT1 Copy} Number Alteration

To determine if a link exists between POFUT1 chromosomic region state $(20 \mathrm{q} 11.21)$ and its overexpression, an in silico analysis was performed. The study showed that among 613 patients with CRC, $76.02 \%$ had an amplification of the 20q11.21 region, which correlated, in 90.13\% of cases, with the increase in POFUT1 expression compared to healthy patients (Figure 3A). Interestingly, around $80 \%$ of CRC patients who had no 20q11.21 amplification presented a lower POFUT1 expression compared to healthy patients. A significant positive correlation exists between copy number and POFUT1 expression $\left(\mathrm{r}_{\mathrm{S}}=0.774, p<0.001\right)$ (Figure 3B), suggesting that POFUT1 transcript quantity is predominantly due to the gene copy number. Furthermore, copy number analysis of POFUT1 gene showed that 20q11.21 chromosomic region amplification mostly generates between two and three POFUT1 copies per genome (49\%) and no more than six copies (Figure 3C). Copy number analysis performed on six selected CRC tumors including those immunolabeled by anti-POFUT1 revealed an increase of POFUT1 copy number in five patients with in majority of cases between 2 and 3 copies, like in bioinformatics analysis (Figure 3D). 


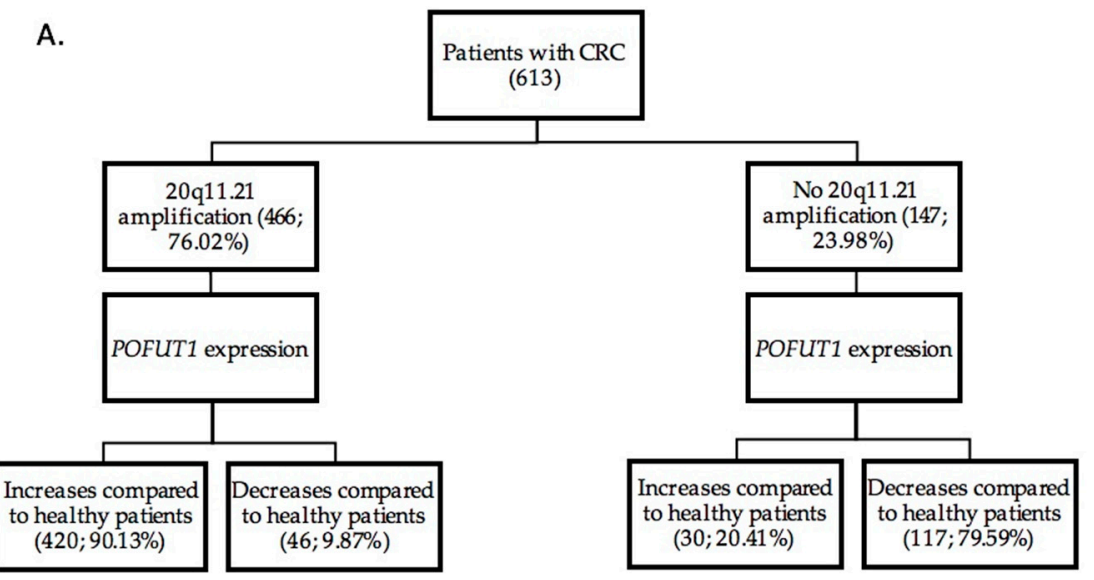

B.

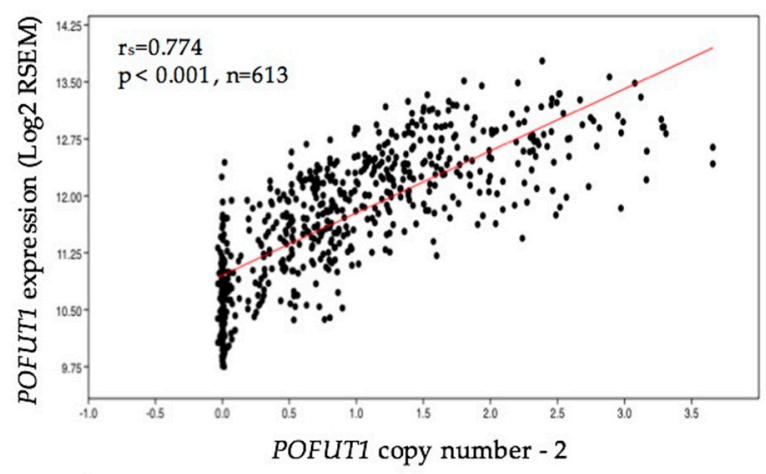

C.

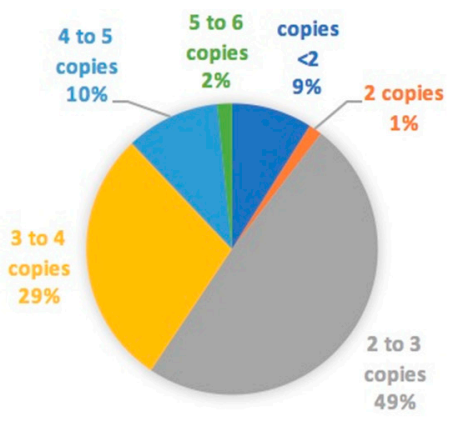

D.

\begin{tabular}{|c|c|c|c|c|c|}
\hline $\begin{array}{l}\text { Patient } \\
\text { samples }\end{array}$ & Gender & Age & $\begin{array}{c}\text { TNM } \\
\text { classification }\end{array}$ & $\begin{array}{c}\text { Pathologic } \\
\text { stage }\end{array}$ & $\begin{array}{c}\text { POFUT1 copy } \\
\text { number }\end{array}$ \\
\hline Normal & $\mathrm{F}$ & 31 & $T$ & T & 2 \\
\hline 17A12993 & $\mathrm{M}$ & 87 & pT3 pN0 & II & 2.02 \\
\hline 17A11438 & $\mathrm{F}$ & 87 & pT3 pN0 & II & 2.41 \\
\hline 17A15152 & $\bar{M}$ & 64 & pT3 N1a M1a & IV & 2.45 \\
\hline 17A16157 & $\mathrm{F}$ & 78 & pT2(m)N1a R0 & III & 2.46 \\
\hline $17 \mathrm{~A} 13270$ & $\bar{M}$ & 70 & pT4aN2aM1c & IV & 2.68 \\
\hline 17A21181 & $\mathrm{F}$ & 87 & pT2N0 R0 & I & 3.03 \\
\hline
\end{tabular}

Figure 3. POFUT1 overexpression is strongly correlated with gene copy number variation. (A) Hierarchical analysis of 613 RNAseq data concerning POFUT1 shows that $76.02 \%$ of CRC patients have an amplification of 20q11.21 chromosomic region where POFUT1 is located. Among them $90.13 \%$ have a POFUT1 overexpression compared to the POFUT1 mean expression in non-tumor adjacent tissues. (B) Spearman Rho correlation analysis in 613 CRC patients shows that POFUT1 expression is significantly correlated with its copy number. To only view additional copies of POFUT1 gene, a subtraction of two copies corresponding to a physiological state is applied for each sample. (C) CRC patients have in the majority of cases between two and three POFUT1 gene copies. (D) POFUT1 copy number analysis performed on gDNA extracted from six CRC and one normal tissues shows an increase of POFUT1 copy number in five CRC cases compared to the normal sample.

\subsection{Correlation between POFUT1 and NOTCH Receptor Expressions}

Since the cross talk between POFUT1 and NOTCH receptors has been demonstrated in hepatocellular carcinoma and gastric cancer [32,33], a Spearman's correlation coefficient was used to determine their relationships in CRC. A significant positive correlation was observed between POFUT1 and NOTCH1 $\left(\mathrm{r}_{\mathrm{s}}=0.34, p<0.001\right)$, NOTCH3 $\left(\mathrm{r}_{\mathrm{s}}=0.087, p=0.0297\right)$ and NOTCH4 $\left(\mathrm{r}_{\mathrm{s}}=0.097\right.$, 
$p=0.0148$ ) receptors (Figure 4). Furthermore, a significant negative correlation was detected between POFUT1 and NOTCH2 $\left(\mathrm{r}_{\mathrm{s}}=-0.098, p=0.0142\right)$. Among all correlations, POFUT1/NOTCH1 one was the strongest.

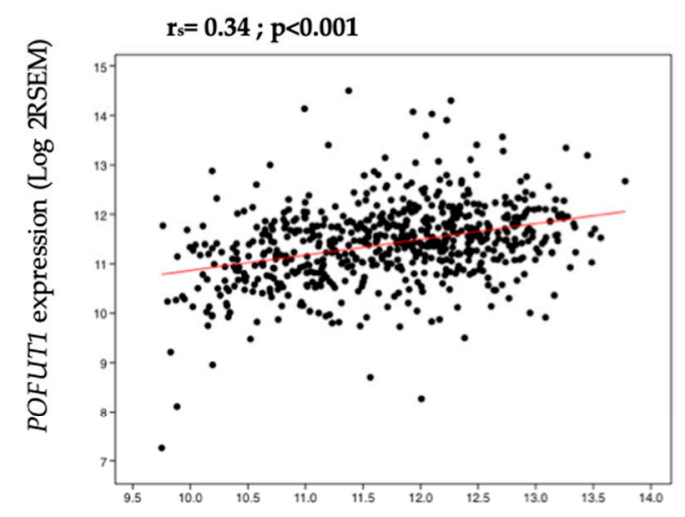

NOTCH1 expression (Log2 RSEM)

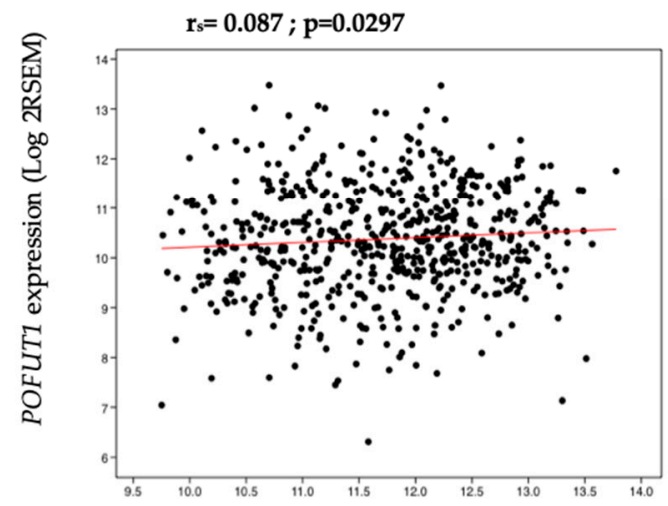

NOTCH3 expression (Log2 RSEM)

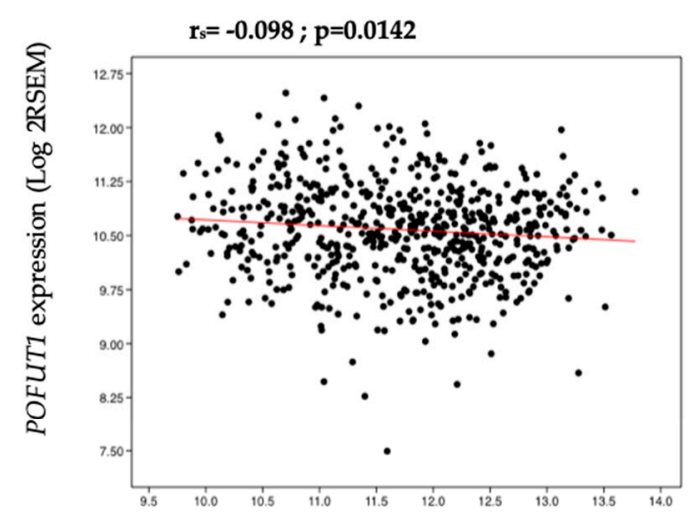

NOTCH2 expression (Log2 RSEM)

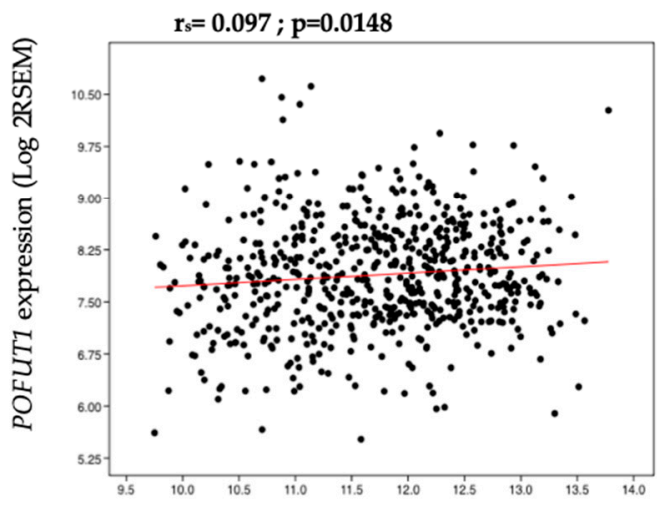

NOTCH4 expression (Log2 RSEM)

Figure 4. Correlation analysis between POFUT1 and all NOTCH receptor expressions. A total of $626 \mathrm{CRC}$ data for each gene is used for a Spearman Rho correlation. In all of cases, POFUT1 expression is significantly correlated with NOTCH receptor expressions.

\subsection{NOTCH Signaling Pathway is Deregulated in CRC}

Although the expressions of POFUT1 and NOTCH1 receptor are significantly and positively correlated, it is necessary to characterize the expression of the NOTCH target genes in order to highlight a potential deregulation of the signaling pathway. We were interested in HES/HEY transcription factor gene family especially HES1 and HEY1 widely studied in NOTCH pathway analysis, p21 (CDKN1A) and Cyclin D1 (CCND1) that encode cell cycle regulators, $c-M y c$ (MYC) which is an oncogene, Snail 1 (SNAI1) implicated in EMT and Survivin (BIRC5) related to apoptosis regulation (Figure 5). All genes, except $H E S 1$, are significantly modified in their expression levels in tumor compared to normal tissues $(p<0.001)$. Cyclin D1 and $c-M y c$ that induce proliferation, Snail 1 that promotes EMT and Survivin that inhibits apoptosis are overexpressed. $p 21$, a negative regulator of cell cycle, and HEY1 transcription factor mediator of Notch signaling, are downregulated. Taken together these results demonstrate that NOTCH signaling is altered in CRC. 


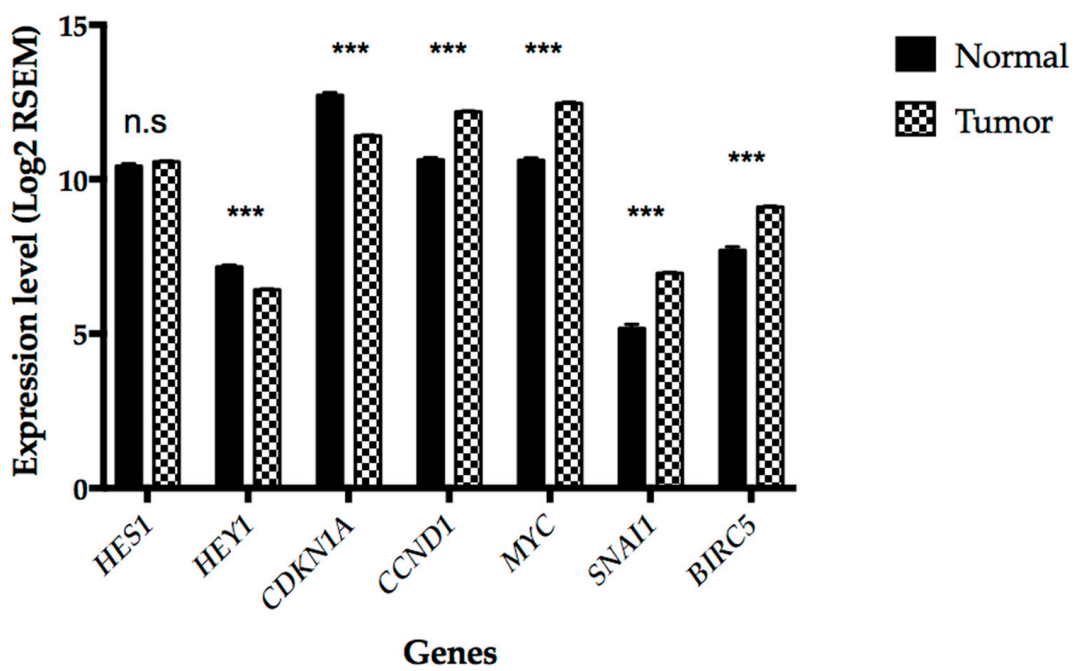

Figure 5. Expression of a set of NOTCH target genes. Data extracted from FireBrowse were obtained from 626 CRC and 51 normal adjacent tissues. The genes related to proliferation ( $p 21, c-M y c$ and Cyclin D1), EMT (Epithelial-to-Mesenchymal Transition) process (Snail 1) and apoptosis (Survivin) are altered in their expressions in the sense of promoting tumor development. ${ }^{* * *} p<0.001$.

\subsection{Relationship between POFUT1, NOTCH1 Expressions, and Clinical Features}

To further explore the association between POFUT1 and NOTCH1 in CRC progression, analysis of their expressions compared to the mean value of healthy patients was studied in the light of various clinical parameters in CRC patients (Tables 1 and 2). POFUT1 expression is significantly associated with tumor issue site ( $p=0.0001$ ), overexpressed in $68.9 \%$ of colon and $84.6 \%$ of rectum tissues (Table 1 ). It is linked to pathologic stage ( $p=0.00019)$ and markedly overexpressed in $79 \%$ of stage I, $63.3 \%$ of stage II, $74.9 \%$ of stage III and $85.2 \%$ of stage IV. POFUT1 expression is associated with M classification ( $p=0.01087$ ) and overexpressed in $70.7 \%$ of M0 stage and $83.9 \%$ of M1 stage. In addition, POFUT1 is differently expressed according to histological type $(p=0.00001)$ with an overexpression in $75 \%$ of colon adenocarcinoma, $30.6 \%$ of colon mucinous adenocarcinoma, $88.4 \%$ of rectal adenocarcinoma and $46.2 \%$ of rectal mucinous adenocarcinoma. However, no correlation was observed between POFUT1 expression and gender, age, $\mathrm{T}$ and $\mathrm{N}$ classifications.

Table 1. Correlation between POFUT1 expression and clinical parameters in patients with CRC.

\begin{tabular}{|c|c|c|c|c|}
\hline \multirow{2}{*}{ Clinical Parameters } & \multirow{2}{*}{$\mathbf{N}$} & \multicolumn{2}{|c|}{ POFUT1 } & \multirow{2}{*}{$p$ Value } \\
\hline & & High (\%) & Low $(\%)$ & \\
\hline \multicolumn{5}{|l|}{ Gender } \\
\hline Female & 290 & $203(70.0)$ & $87(30.0)$ & \multirow{2}{*}{0.10206} \\
\hline Male & 331 & $251(75.8)$ & $80(24.2)$ & \\
\hline \multicolumn{5}{|l|}{ Age (years) } \\
\hline$\leq 60$ & 193 & $146(75.6)$ & $47(24.4)$ & \multirow{2}{*}{0.38296} \\
\hline$>60$ & 426 & 308 (72.3) & $118(27.7)$ & \\
\hline \multicolumn{5}{|l|}{ Tumor Issue Site } \\
\hline Colon & 454 & $313(68.9)$ & $141(31.1)$ & \multirow{2}{*}{0.00010} \\
\hline Rectum & 163 & $138(84.6)$ & $25(15.4)$ & \\
\hline \multicolumn{5}{|l|}{ Pathologic Stage } \\
\hline Stage I & 105 & $83(79.0)$ & $22(21.0)$ & \multirow{4}{*}{0.00019} \\
\hline Stage II & 229 & $145(63.3)$ & $84(36.7)$ & \\
\hline Stage III & 179 & $134(74.9)$ & $45(25.1)$ & \\
\hline Stage IV & 88 & $75(85.2)$ & $13(14.8)$ & \\
\hline
\end{tabular}


Table 1. Cont.

\begin{tabular}{|c|c|c|c|c|}
\hline \multirow{2}{*}{ Clinical Parameters } & \multirow{2}{*}{$\mathbf{N}$} & \multicolumn{2}{|c|}{ NOTCH1 } & \multirow{2}{*}{$p$ Value } \\
\hline & & High (\%) & Low (\%) & \\
\hline \multicolumn{5}{|l|}{ Pathology T Stage } \\
\hline $\mathrm{T} 1$ & 20 & $17(85.0)$ & $3(15.0)$ & \multirow{4}{*}{0.16581} \\
\hline $\mathrm{T} 2$ & 105 & $84(80.0)$ & $21(20.0)$ & \\
\hline $\mathrm{T} 3$ & 423 & $300(70.9)$ & $123(29.1)$ & \\
\hline $\mathrm{T} 4$ & 70 & $50(71.4)$ & $20(28.6)$ & \\
\hline \multicolumn{5}{|l|}{ Pathology N Stage } \\
\hline No & 352 & $245(69.6)$ & $107(30.4)$ & \multirow{3}{*}{0.05423} \\
\hline N1 & 150 & $120(80.0)$ & $30(20.0)$ & \\
\hline N2 & 115 & $85(73.9)$ & $30(26.1)$ & \\
\hline \multicolumn{5}{|l|}{ Pathology M Stage } \\
\hline M0 & 460 & $325(70.7)$ & $135(29.3)$ & \multirow{2}{*}{0.01087} \\
\hline M1 & 87 & $73(83.9)$ & $14(16.1)$ & \\
\hline \multicolumn{5}{|l|}{ Histological Type } \\
\hline Colon adenocarcinoma & 388 & $291(75.0)$ & $97(25.0)$ & \multirow{4}{*}{0.00001} \\
\hline Colon mucinous adenocarcinoma & 62 & $19(30.6)$ & $43(69.4)$ & \\
\hline Rectal adenocarcinoma & 147 & $130(88.4)$ & $17(11.6)$ & \\
\hline Rectal mucinous adenocarcinoma & 13 & $6(46.2)$ & $7(53.8)$ & \\
\hline
\end{tabular}

Bold values indicate statistical significance.

NOTCH1 expression was significantly associated with tumor issue site $(p=0.00099)$ and overexpressed in $70.9 \%$ of colon and $84 \%$ of rectum tissues (Table 2). It is associated to histological type $(p=0.00173)$ and NOTCH1 is overexpressed in $73.2 \%$ of colon adenocarcinoma, $59.7 \%$ of colon mucinous adenocarcinoma, $84.4 \%$ of rectal adenocarcinoma and $76.9 \%$ of rectal mucinous adenocarcinoma. No correlation was observed between NOTCH1 expression and gender, age, pathological stage, $\mathrm{T}, \mathrm{N}$ and $\mathrm{M}$ classifications.

Table 2. Correlation between NOTCH1 expression and clinical parameters in patients with CRC.

\begin{tabular}{|c|c|c|c|c|}
\hline \multirow{2}{*}{ Clinical Parameters } & \multirow{2}{*}{$\mathbf{N}$} & \multicolumn{2}{|c|}{ NOTCH1 } & \multirow{2}{*}{$p$ Value } \\
\hline & & High (\%) & Low (\%) & \\
\hline \multicolumn{5}{|l|}{ Gender } \\
\hline Female & 290 & $214(73.8)$ & $76(26.2)$ & \multirow{2}{*}{0.74724} \\
\hline Male & 331 & 248 (74.9) & $83(25.1)$ & \\
\hline \multicolumn{5}{|l|}{ Age (years) } \\
\hline$\leq 60$ & 193 & $141(73.1)$ & $52(26.9)$ & \multirow{2}{*}{0.58601} \\
\hline$>60$ & 426 & $320(75.1)$ & $106(24.9)$ & \\
\hline \multicolumn{5}{|l|}{ Tumor Issue Site } \\
\hline Colon & 454 & $322(70.9)$ & $132(29.1)$ & \multirow{2}{*}{0.00099} \\
\hline Rectum & 163 & $137(84.0)$ & $26(16.0)$ & \\
\hline \multicolumn{5}{|l|}{ Pathologic Stage } \\
\hline Stage I & 105 & $80(76.2)$ & $25(23.8)$ & \multirow{4}{*}{0.59717} \\
\hline Stage II & 229 & $163(71.2)$ & $66(28.8)$ & \\
\hline Stage III & 179 & $135(75.4)$ & $44(24.6)$ & \\
\hline Stage IV & 88 & $68(77.3)$ & $20(22.7)$ & \\
\hline
\end{tabular}


Table 2. Cont

\begin{tabular}{|c|c|c|c|c|}
\hline \multirow{2}{*}{ Clinical Parameters } & \multirow{2}{*}{$\mathbf{N}$} & \multicolumn{2}{|c|}{ NOTCH1 } & \multirow{2}{*}{$p$ Value } \\
\hline & & High (\%) & Low $(\%)$ & \\
\hline \multicolumn{5}{|l|}{ Pathology T Stage } \\
\hline $\mathrm{T} 1$ & 20 & $11(55.0)$ & $9(45.0)$ & \multirow{4}{*}{0.16062} \\
\hline $\mathrm{T} 2$ & 105 & $79(75.2)$ & $26(24.8)$ & \\
\hline $\mathrm{T} 3$ & 423 & $313(74.0)$ & $110(26.0)$ & \\
\hline $\mathrm{T} 4$ & 70 & $56(80.0)$ & $14(20.0)$ & \\
\hline \multicolumn{5}{|l|}{ Pathology N Stage } \\
\hline No & 352 & $257(73.0)$ & $95(27.0)$ & \multirow{3}{*}{0.66047} \\
\hline N1 & 150 & $114(76.0)$ & $36(24.0)$ & \\
\hline N2 & 115 & $88(76.5)$ & $27(23.5)$ & \\
\hline \multicolumn{5}{|l|}{ Pathology M Stage } \\
\hline M0 & 460 & $335(72.8)$ & $125(27.2)$ & \multirow{2}{*}{0.41731} \\
\hline M1 & 87 & $67(77.0)$ & $20(23.0)$ & \\
\hline \multicolumn{5}{|l|}{ Histological Type } \\
\hline Colon adenocarcinoma & 388 & $284(73.2)$ & $104(26.8)$ & \multirow{4}{*}{0.00173} \\
\hline Colon mucinous adenocarcinoma & 62 & $37(59.7)$ & $25(40.3)$ & \\
\hline Rectal adenocarcinoma & 147 & $124(84.4)$ & $23(15.6)$ & \\
\hline Rectal mucinous adenocarcinoma & 13 & $10(76.9)$ & $3(23.1)$ & \\
\hline
\end{tabular}

Bold values indicate statistical significance.

In addition, we classified CRC patients into four groups according to their combined expression status of POFUT1 and NOTCH1 as follow: high POFUT1/high NOTCH1, low POFUT1/low NOTCH1, high POFUT1/low NOTCH1 and low POFUT1/high NOTCH1. The threshold value which allows to classify individuals in the high and low groups is the mean expression value of POFUT1 and NOTCH1 in healthy patients. The associations between these groups and clinical features were analyzed in Table 3. Combined POFUT1/NOTCH1 expressions were significantly associated with tumor issue site $(p=0.00004)$, pathologic stage $(p=0.00498)$ and histological type $(p<0.001)$. It should be noted that in all cases, the majority of CRC are located in high/high group.

Table 3. Correlation between POFUT1/NOTCH1 expressions and clinical parameters in patients with CRC.

\begin{tabular}{|c|c|c|c|c|c|c|}
\hline \multirow{2}{*}{ Clinical Parameters } & \multirow{2}{*}{$\mathbf{N}$} & \multicolumn{4}{|c|}{ POFUT1/NOTCH1 } & \multirow{2}{*}{$p$ Value } \\
\hline & & High/High (\%) & Low/Low (\%) & High/Low (\%) & Low/High (\%) & \\
\hline \multicolumn{7}{|l|}{ Gender } \\
\hline Female & 290 & $169(58.3)$ & $42(14.5)$ & $34(11.7)$ & $45(15.5)$ & \multirow{2}{*}{0.4020} \\
\hline Male & 331 & $205(61.9)$ & $37(11.2)$ & $46(13.9)$ & $43(13.0)$ & \\
\hline \multicolumn{7}{|l|}{ Age (years) } \\
\hline$\leq 60$ & 193 & $116(60.1)$ & $22(11.4)$ & $30(15.5)$ & $25(13.0)$ & \multirow{2}{*}{0.56050} \\
\hline$>60$ & 426 & $258(60.6)$ & $56(13.1)$ & $50(11.7)$ & $62(14.6)$ & \\
\hline \multicolumn{7}{|l|}{ Tumor Issue Site } \\
\hline Colon & 454 & $248(54.6)$ & $67(14.8)$ & $65(14.3)$ & $74(16.3)$ & \multirow{2}{*}{0.00004} \\
\hline Rectum & 163 & $124(76.1)$ & $12(7.4)$ & $14(8.6)$ & $13(8.0)$ & \\
\hline \multicolumn{7}{|l|}{ Pathologic Stage } \\
\hline Stage I & 105 & $68(64.8)$ & $10(9.5)$ & $15(14.3)$ & $12(11.4)$ & \multirow{4}{*}{0.00498} \\
\hline Stage II & 229 & $123(53.7)$ & $44(19.2)$ & $22(9.6)$ & $40(17.5)$ & \\
\hline Stage III & 179 & $107(59.8)$ & $17(9.5)$ & $27(15.1)$ & $28(15.6)$ & \\
\hline Stage IV & 88 & $62(70.5)$ & $7(8)$ & $13(14.8)$ & $6(6.8)$ & \\
\hline
\end{tabular}


Table 3. Cont.

\begin{tabular}{|c|c|c|c|c|c|c|}
\hline \multirow{2}{*}{ Clinical Parameters } & \multirow{2}{*}{$\mathbf{N}$} & \multicolumn{4}{|c|}{ POFUT1/NOTCH1 } & \multirow{2}{*}{$p$ Value } \\
\hline & & High/High (\%) & Low/Low (\%) & High/Low (\%) & Low/High (\%) & \\
\hline \multicolumn{7}{|l|}{ Pathology T Stage } \\
\hline T1 & 20 & $10(50.0)$ & $2(10.0)$ & $7(35.0)$ & $1(5.0)$ & \multirow{4}{*}{0.09107} \\
\hline $\mathrm{T} 2$ & 105 & $68(64.8)$ & $10(9.5)$ & $16(15.2)$ & $11(10.5)$ & \\
\hline T3 & 423 & $250(59.1)$ & $60(14.2)$ & $50(11.8)$ & $63(14.9)$ & \\
\hline $\mathrm{T} 4$ & 70 & $43(61.4)$ & $7(10.0)$ & $7(10.0)$ & $13(18.6)$ & \\
\hline \multicolumn{7}{|l|}{ Pathology N Stage } \\
\hline No & 352 & $204(58.0)$ & $54(15.3)$ & $41(11.6)$ & $53(15.1)$ & \multirow{3}{*}{0.42789} \\
\hline N1 & 150 & $97(64.7)$ & $13(8.7)$ & $23(15.3)$ & $17(11.3)$ & \\
\hline N2 & 115 & $70(60.9)$ & $12(10.4)$ & $15(13.0)$ & $18(15.7)$ & \\
\hline \multicolumn{7}{|l|}{ Pathology M Stage } \\
\hline M0 & 460 & $266(57.8)$ & $66(14.3)$ & $59(12.8)$ & $69(15.0)$ & \multirow[b]{2}{*}{0.07716} \\
\hline M1 & 87 & $61(70.1)$ & $8(9.2)$ & $12(13.8)$ & $6(6.9)$ & \\
\hline \multicolumn{7}{|l|}{ Histological Type } \\
\hline Colon adenocarcinoma & 388 & 235 (60.6) & $48(12.4)$ & $56(14.4)$ & 49 (12.6) & \multirow{4}{*}{$1.5335 \times 10^{-15}$} \\
\hline Colon mucinous adenocarcinoma & 62 & $12(19.4)$ & $18(29.0)$ & $7(11.3)$ & $25(40.3)$ & \\
\hline Rectal adenocarcinoma & 147 & $116(78.9)$ & $9(6.1)$ & $14(9.5)$ & $8(5.4)$ & \\
\hline Rectal mucinous adenocarcinoma & 13 & $6(46.2)$ & $3(23.1)$ & $0(0)$ & $4(30.8)$ & \\
\hline
\end{tabular}

\section{Discussion}

Comprehension of mechanisms which initiate tumor development is crucial since an early diagnosis of cancer can trigger treatment and increase the patient chances of recovery. Therefore, research of new potential diagnostic markers of cancer occupies a substantial part in the scientific field. Recently, many studies focused on glycosylation, especially in malignant tumor development [41]. In that context, O-fucosylation, linked to expression of Protein O-fucosyltransferase 1 (POFUT1) and its activity on EGF-like domains, appears promising. POFUT1 adds $O$-fucose on $S$ or $T$ residues within the consensus sequence $\mathrm{C}^{2} \mathrm{X}_{4}(\mathrm{~S} / \mathrm{T}) \mathrm{C}^{3}$ of EGF-like domains [42] present in some cell surface and secreted proteins [43]. In humans, 87 putative POFUT1 targets had been referenced [44]. Among those, NOTCH receptors are the most described in literature and their $O$-fucosylation was shown to be essential for their interaction with ligands and therefore for NOTCH signaling [24]. POFUT1 and NOTCH cross talk had been described in two cancer types. In breast cancer, an overexpression of POFUT1 and NOTCH1 was associated with lymph node metastasis and advanced tumor stage [45]. In hepatocellular carcinoma, POFUT1 overexpression induced an aberrant activation of NOTCH pathway switching on HES1, which in turn promoted migration and cell proliferation [32]. Currently, no study focused on the implication of POFUT1 in colorectal cancer, although it is a major public health issue. Colorectal cancer is one of the cancers where POFUT1 is the most overexpressed. Here, bioinformatics combined with immunohistochemistry, western blot and gene copy number analysis had been used as an approach to determine if POFUT1 could be a potential novel CRC biomarker. Among the data of 626 CRC patients available in FireBrowse database, 459 (72.8\%) had a POFUT1 overexpression compared to healthy patients. The overexpression was detected from the first stage of CRC. POFUT1 labeling on CRC biopsies confirmed the overexpression in tumor compared to the adjacent non-tumor tissues. The chromosomic region 20q11.21, where POFUT1 gene is located, appears to be unstable leading to gene copy number variation, which could explain the expression increase [46]. In the CRC panel, we observed a 20q11.21 amplification in 466 cases over $613(76.02 \%)$, which induces an increase of POFUT1 gene copy number to 5.7 copies. Our POFUT1 copy number analysis performed on six CRC tissues follows the same trend as the bioinformatics analysis. As expected, the small sample size does not allow observing the whole range of copy number alterations. A strong positive correlation $\left(\mathrm{r}_{\mathrm{s}}=0.774\right)$ between POFUT1 copy number and its expression argues for a direct link as already noticed [38]. It should be noted that the significant decrease of POFUT1 expression in stage II (Figure 2B) is mainly due to a greater proportion of cases without 20q11.21 chromosomic region amplification (33.9\%) compared to other 
stages (Stage I, 23.1\%; Stage III, 18.0\%; Stage IV, 13.8\%). Significant correlations between POFUT1 and NOTCH receptor expressions were measured with the strongest for POFUT1/NOTCH1 association $\left(\mathrm{r}_{\mathrm{S}}=0.34\right)$. POFUT1, NOTCH1 and POFUT1/NOTCH1 high expressions are significantly associated with the tumor issue site, preferentially overexpressed in rectum tissue $(84.6 \%, 84 \%, 76.1 \%$, respectively). Several other studies highlighted different gene expressions and genetic features associated with carcinogenesis between colon and rectum [47,48]. Interestingly, POFUT1, and not NOTCH1, expression appears to be significantly associated with M classification. POFUT1 is predominantly overexpressed in colorectal metastasis $(83.9 \%$ ) and could O-fucosylate other protein targets than NOTCH receptors, such as AGRIN which was shown to enhance tumor progression by activating cell migration and invasion in oral cancer [49]. Overexpression of POFUT1 and NOTCH1 is preferentially observed in non-mucinous adenocarcinoma histological type. This observation can be explained by the fact that mucinous adenocarcinoma are characterized by a markedly reduced rate of copy-number aberrations compared to adenocarcinoma [50]. Indeed, in mucinous adenocarcinoma, only $42.6 \%$ of cases had an amplified 20q11.21 region. Regarding NOTCH signaling activation, it is known that in tumor tissues a greater activation of NOTCH pathway is involved in cell proliferation and metastasis process [51,52]. In this study on CRC, an increase of NOTCH activation is supported by the higher expression levels of its target genes such as p21, Cyclin D1, c-Myc, Survivin and Snail 1. However, the expression of HES1, a proved Notch signaling downstream target, is not modified in tumor compared to healthy tissues (Figure 5). Nevertheless, studies in relation with HES1 expression in CRC are controversial [53-55] suggesting that it is not a good marker of NOTCH signaling activation in colorectal cancer. We also showed that HEY1 expression is downregulated although this gene is also known to be activated by Notch signaling [56,57]. As well, conflicting studies showed that this NOTCH target transcriptional factor was overexpressed [58] or non-expressed [59] in colorectal cancer. Surprisingly, significant positive correlations between the expressions of POFUT1 and HES1 or HEY1 are found for healthy tissues and not for tumor ones (Figure S1). It could be explained by the cell heterogeneity of tumors. Therefore, the consequences of POFUT1 overexpression on NOTCH signaling activation could be opposite depending on the NOTCH target genes. The effect of POFUT1 overexpression on $O$-fucosylation levels and NOTCH signaling would be cell-type dependent. Overexpression of POFUT1 most likely does not result in increased $O$-fucosylation of NOTCH receptors. Indeed, in HEK293T cells, most EGF-like repeats containing $O$-fucose consensus sequences are $O$-fucosylated at high stoichiometry degree [60]. If it is the case in colorectal cancer, the overexpression of POFUT1 may affect the O-fucosylation state of other proteins. Nevertheless, it is important to note that in the majority of CRC cases analyzed in the present study, both POFUT1 and NOTCH1 are overexpressed (60.5\%), suggesting that overexpression of POFUT1 is necessary to ensure $O$-fucosylation of additional NOTCH receptors in the tumor. Finally, in addition to its $O$-fucosyltransferase activity, it had been demonstrated an independent chaperone function for the POFUT1 orthologue in Drosophila melanogaster [61]. However, this additional function is still controversial in mammals [24]. Ajima et al. (2017) [62] showed that in mouse it is not possible to dissociate the possible chaperone contribution from its $O$-fucosyltransferase activity, which could also be the case for human POFUT1. Our study focuses on POFUT1 expression level related to its copy number determined by 20q11.21 chromosomic region state. Nevertheless we cannot exclude that gene expression level can also be modified by other mechanisms such as mutations within promoter or by miR-34 family regulation [63]. The lack of these informations in the database did not allow us to explore these expression regulatory mechanisms.

\section{Materials and Methods}

\subsection{The Cancer Genome Atlas Data Analysis}

Data for colorectal carcinoma were extracted from FireBrowse database (http://www. firebrowse.org). A total of 626 tumor samples and 51 normal samples were studied. Gene expression levels were merged from COADREAD.uncv2.mRNAseq_RSEM_normalized_log2.txt 
found in COADREAD.mRNAseq_Preprocess.Level file. Clinical features for each patient were determined from "CLI_years_to_birth", "CLI_tumor_tissue_site", "CLI_pathologic_stage", "CLI_pathology_T_stage", "CLI_pathology_N_stage", “CLI_pathology_M_stage", “CLI_gender" and "CLI_histological_type" extracted from COADREAD-TP.samplefeatures.txt available in COADREAD-TP.Aggregate_AnalysisFeatures.Level metadata. POFUT1 gene copy number was retrieved from all_data_by_genes.txt provided in COADREAD-TP.CopyNumber_GISTIC2.Level metadata. The presence or absence of 20q11.21 chromosomic region amplification was found in transformed.cor.cli from COADREAD-TP.Correlate_Clinical_vs_CopyNumber-Focal.Level metadata.

\subsection{Statistical Analysis}

Statistical analyses were performed using Past3 3.20 version [64] and GraphPad Prism 7 (GraphPad Software Inc, San Diego, CA, USA). mRNA expression data were referenced as mean \pm SEM and a t-Student test was applied to compare values between normal and tumor tissues. Bivariate correlation analysis between POFUT1 and NOTCH receptor mRNA expressions was performed using Spearman's Rho. Associations between POFUT1, NOTCH1 expressions and clinicopathological parameters were estimated by a Chi-square test. Results were considered statistically significant if the p-value was less than 0.05 .

\subsection{Genomic DNA Extraction and POFUT1 Copy Number Analysis}

Genomic DNA was extracted from normal and tumor tissues with Maxwell ${ }^{\circledR} 16$ FFPE Plus LEV DNA Purification Kit and Maxwell ${ }^{\circledR} 16$ IVD device (Promega, Madison, WI, USA) according to the manufacturer's protocol. Genomic DNA concentration was determined using Quantifluor ${ }^{\circledR}$ ONE dsDNA system (Promega) and measured with Quantus ${ }^{\mathrm{TM}}$ Fluorometer (Promega) following manufacturer's recommendations. Taqman ${ }^{\mathrm{TM}}$ copy number assay for POFUT1 (Hs02487189_cn) and RNAse P reference assays (4403326) were used with Gene Expression Master Mix (Applied Biosystems $^{\mathrm{TM}}$, Thermo Fisher Scientific, Waltham, MA, USA), according to product literature. Twenty nanograms of gDNA were run in triplicate on QuantStudio 3 real-time PCR system (Applied Biosystem $^{\mathrm{TM}}$ ). POFUT1 copy number was estimated using $\Delta \Delta \mathrm{Ct}$ method [65].

\subsection{POFUT1 Labelling by Immunohistochemistry}

Paraffin-embedded blocks of six colorectal adenocarcinomas corresponding to each CRC pathological stage were obtained from the Tumor Bank (CRBiolim) of Limoges University Hospital. Immunohistochemical analysis was performed on five- $\mu \mathrm{m}$-thick paraffin sections with anti-POFUT1 antibody (1/25, ab74302, Abcam, Cambridge, UK). Slides were automatically processed (Ventana Benchmark ULTRA, Roche, Meylan, France) according to the protocol supplied by the manufacturer. Images were acquired with NanoZoomer RS 2.0 Hamamatsu (Hamamatsu Photonics, Massy, France). All samples were used in accordance with French bioethics laws regarding patient information and consent. Ethics approval (CRB-CESSION-2018-016) was obtained from the "Comité médico-scientifique de la tumorothèque de l'Hôpital Dupuytren", the bioethics committee of our hospital.

\subsection{POFUT1 Labeling by Immunofluorescence}

Colorectal cancer cell lines, HCT 116 and SW620 obtained from ATCC and the stably transfected cell lines, HCT 116 shPOFUT1 and SW620 shPOFUT1, created by our team were fixed with $4 \%$ paraformaldehyde in PBS for $30 \mathrm{~min}$ at room temperature and permeabilized with HEPES Triton buffer (20 mM HEPES, $300 \mathrm{mM}$ sucrose, $50 \mathrm{mM} \mathrm{NaCl}, 3 \mathrm{mM} \mathrm{MgCl} 2,0.5 \%$ Triton X-100, pH 7.4) for $30 \mathrm{~min}$ at $4{ }^{\circ} \mathrm{C}$. After three washes with PBS, non-specific binding sites were saturated for $1 \mathrm{~h}$ at room temperature with a blocking solution containing $10 \%$ goat serum, $1 \%$ BSA, $0.1 \%$ Triton X-100 in PBS. After one wash with PBS/0.2\% BSA, immunolabeling was performed with anti-POFUT1 (ab74302) antibody diluted at $1: 100$ in PBS/1\% BSA overnight at $4{ }^{\circ} \mathrm{C}$. After washes with PBS and PBS $/ 0.2 \%$ BSA $/ 0.1 \%$ Tween-20, cells were incubated with the $\mathrm{F}\left(\mathrm{ab}^{\prime}\right) 2$ fragment of goat anti-rabbit $\operatorname{IgG}(\mathrm{H}+\mathrm{L})$ 
secondary antibody Alexa fluo ${ }^{\circledR} 546$ conjugated (Molecular Probes, Life Technology, Eugene, OR, USA) used at 1:1000 in PBS/1\% BSA for $15 \mathrm{~min}$ in dark at room temperature. After new washes, nuclei were stained with DAPI (Thermo Fisher Scientific) at $1 \mu \mathrm{g} \cdot \mathrm{mL}^{-1}$ in PBS, $5 \mathrm{~min}$ in dark at room temperature. Finally, after three PBS washes, cells were mounted on slides with Fluoromount- $G^{\circledR}$ (SouthernBiotech, Birmingham, AL, USA) and sealed with glass coverslips. We used the MetaMorph ${ }^{\circledR}$ software (Molecular Devices, Sunnyvale, CA, USA) to acquire images with a LEICA microsystem DMI6000B inverted epifluorescence microscope.

\subsection{Protein Extraction and Western Blot}

Total cell protein extracts were prepared by solubilizing tissue or cell pellets (from CCD841CoN, HCT 116, HT-29 and SW620 cell lines obtained from ATCC) in a RIPA lysis buffer (50 mM Tris-HCl, $150 \mathrm{mM} \mathrm{NaCl}, 1 \%$ Triton X-100 (v/v), $0.5 \%$ sodium deoxycholate $(w / v), 0.1 \%$ sodium dodecylsulfate $(v / v), \mathrm{pH} 8)$ and a cocktail of protease and phosphatase inhibitors (Roche Applied Science, Mannheim, Germany) for $1 \mathrm{~h} 30 \mathrm{~min}$ at $4{ }^{\circ} \mathrm{C}$. Protein lysates were centrifuged at $12,000 \times \mathrm{g}$ for $20 \mathrm{~min}$ at $4{ }^{\circ} \mathrm{C}$, and protein supernatant concentrations were determined using Pierce ${ }^{\mathrm{TM}} \mathrm{BCA}$ protein assay kit (Thermo Scientific ${ }^{\mathrm{TM}}$, Rockford, IL, USA) with bovine serum albumin (BSA) as a standard. Equal amounts of proteins $(25$ or $50 \mu \mathrm{g}$ ) were resolved by SDS-PAGE using 12\% polyacrylamide gels for $1 \mathrm{~h}$ at $20 \mathrm{~mA}$. Proteins were transferred onto Amersham ${ }^{\mathrm{TM}}$ Protra ${ }^{\circledR}$ premium $0.2 \mu \mathrm{m}$ nitrocellulose (GE Healthcare, Buckinghamshire, UK) for $1 \mathrm{~h} 30 \mathrm{~min}$ at $0.8 \mathrm{~mA} / \mathrm{cm}^{2}$. Membranes were blocked with TBS (50 mM Tris, $150 \mathrm{mM} \mathrm{NaCl}$, $\mathrm{pH}$ 7.6) supplemented with $0.1 \%$ Tween-20 (v/v) (TBST) and 5\% (w/v) non-fat dry milk during $1 \mathrm{~h}$ at room temperature. They were incubated with anti-POFUT1 [39], anti-GAPDH (AF5718, R\&D Systems, Minneapolis, MN, USA) or anti-Actin (sc-1615, Santa Cruz Biotechnology, Santa Cruz, CA, USA) antibodies, diluted at 1:1000 in TBST, 2.5\% (w/v) non-fat dry milk overnight at $4{ }^{\circ} \mathrm{C}$. After three washes with TBST, membranes were incubated with secondary antibodies (anti-goat or anti-rabbit HRP-conjugated IgG, Dako, Glostrup, Denmark) diluted at 1:1000 in TBST, 2.5\% (w/v) non-fat dry milk for $1 \mathrm{~h}$ at room temperature. After three washes in TBST, reactive proteins were visualized with ECL ${ }^{\mathrm{TM}}$ Prime Western blotting system (GE Healthcare, Uppsala, Sweden). For detection and relative quantification of band intensities, we used Amersham Imager 600 device (GE Healthcare).

\section{Conclusions}

In conclusion, our findings indicated that POFUT1 is overexpressed in colorectal cancer driven in majority of cases by a 20q11.21 chromosomic region amplification. This aberrant expression may promote carcinogenesis by NOTCH pathway activation. Finally, targeting POFUT1 seems to be a promising strategy for CRC diagnosis.

Supplementary Materials: The following are available online at http:/ /www.mdpi.com/2072-6694/10/11/411/ s1, Figure S1: Correlation analysis between POFUT1 and HES1, HEY1 transcription factor expressions.

Author Contributions: A.G. and A.M. contributed to the study concept. J.C. collected and analyzed data and wrote the initial draft of the manuscript. A.G., F.L. and A.M. assisted in the preparation of the manuscript. A.C. choose analyzed tumors in Tumor Bank and F.L. validated them. A.C. supervised tumors immunolabeling. All authors reviewed and approved the manuscript.

Funding: This work was supported by a French Ministry of Higher Education and Research doctoral fellowship to J.C. The work was funded by the GlyCanColor project within the CORC program.

Acknowledgments: We gratefully acknowledge Karine Durand for image acquisitions and Daniel Petit for his help in statistics. We are grateful to Pr. Bertrand Liagre and his team for providing us with the wild-type HCT 116, HT-29 and SW620; and to Dr. Anne Harduin-Lepers for providing us with CC841CoN.

Conflicts of Interest: The authors declare no conflict of interest. 


\section{References}

1. Global Burden of Disease Cancer Collaboration; Fitzmaurice, C.; Allen, C.; Barber, R.M.; Barregard, L.; Bhutta, Z.A.; Brenner, H.; Dicker, D.J.; Chimed-Orchir, O.; Dandona, R.; et al. Global, Regional, and National Cancer Incidence, Mortality, Years of Life Lost, Years Lived with Disability, and Disability-Adjusted Life-years for 32 Cancer Groups, 1990 to 2015: A Systematic Analysis for the Global Burden of Disease Study. JAMA Oncol. 2017, 3, 524. [CrossRef] [PubMed]

2. Hisamuddin, I.M.; Yang, V.W. Genetics of Colorectal Cancer. Med. Gen. Med. 2004, 6, 13.

3. Dennis, J.W.; Granovsky, M.; Warren, C.E. Protein glycosylation in development and disease. BioEssays 1999, 21, 412-421. [CrossRef]

4. Dube, D.H.; Bertozzi, C.R. Glycans in cancer and inflammation-Potential for therapeutics and diagnostics. Nat. Rev. Drug Discov. 2005, 4, 477-488. [CrossRef] [PubMed]

5. Shental-Bechor, D.; Levy, Y. Folding of glycoproteins: Toward understanding the biophysics of the glycosylation code. Curr. Opin. Struct. Biol. 2009, 19, 524-533. [CrossRef] [PubMed]

6. Varki, A.; Cummings, R.D.; Esko, J.D.; Freeze, H.H.; Stanley, P.; Bertozzi, C.R.; Hart, G.W.; Etzler, M.E. Essentials of Glycobiology, 2nd ed.; Chapter 6; Cold Spring Harbor Laboratory Press: Cold Spring Harbor, NY, USA, 2009; ISBN 978-0-87969-770-9.

7. Dennis, J.W.; Nabi, I.R.; Demetriou, M. Metabolism, Cell Surface Organization, and Disease. Cell 2009, 139, 1229-1241. [CrossRef] [PubMed]

8. Natsuka, S.; Lowe, J.B. Enzymes involved in mammalian oligosaccharide biosynthesis. Curr. Opin. Struct. Biol. 1994, 4, 683-691. [CrossRef]

9. Kansas, G.S. Selectins and their ligands: Current concepts and controversies. Blood 1996, 88, 3259-3287. [PubMed]

10. Aplin, J.D.; Jones, C.J. Fucose, placental evolution and the glycocode. Glycobiology 2012, 22, 470-478. [CrossRef] [PubMed]

11. Muinelo-Romay, L.; Vázquez-Martín, C.; Villar-Portela, S.; Cuevas, E.; Gil-Martín, E.; Fernández-Briera, A. Expression and enzyme activity of $\alpha(1,6)$ fucosyltransferase in human colorectal cancer: $\alpha(1,6) \mathrm{FT}$ in Human CRC. Int. J. Cancer 2008, 123, 641-646. [CrossRef] [PubMed]

12. Liang, L.; Gao, C.; Li, Y.; Sun, M.; Xu, J.; Li, H.; Jia, L.; Zhao, Y. miR-125a-3p/FUT5-FUT6 axis mediates colorectal cancer cell proliferation, migration, invasion and pathological angiogenesis via PI3K-Akt pathway. Cell Death Dis. 2017, 8, e2968. [CrossRef] [PubMed]

13. Luo, Y.; Nita-Lazar, A.; Haltiwanger, R.S. Two Distinct Pathways for O-fucosylation of Epidermal Growth Factor-like or Thrombospondin Type 1 Repeats. J. Biol. Chem. 2006, 281, 9385-9392. [CrossRef] [PubMed]

14. Yao, D.; Huang, Y.; Huang, X.; Wang, W.; Yan, Q.; Wei, L.; Xin, W.; Gerson, S.; Stanley, P.; Lowe, J.B.; et al. Protein $O$-fucosyltransferase 1 (Pofut1) regulates lymphoid and myeloid homeostasis through modulation of Notch receptor ligand interactions. Blood 2011, 117, 5652-5662. [CrossRef] [PubMed]

15. Der Vartanian, A.; Audfray, A.; Al Jaam, B.; Janot, M.; Legardinier, S.; Maftah, A.; Germot, A. Protein O-fucosyltransferase 1 Expression Impacts Myogenic C2C12 Cell Commitment via the Notch Signaling Pathway. Mol. Cell. Biol. 2015, 35, 391-405. [CrossRef] [PubMed]

16. Wang, Y.; Shao, L.; Shi, S.; Harris, R.J.; Spellman, M.W.; Stanley, P.; Haltiwanger, R.S. Modification of Epidermal Growth Factor-like Repeats with $O$-fucose: Molecular and expression of a novel GDP-fucose protein O-fucosyltransferase. J. Biol. Chem. 2001, 276, 40338-40345. [CrossRef] [PubMed]

17. Luo, Y.; Haltiwanger, R.S. O-fucosylation of Notch Occurs in the Endoplasmic Reticulum. J. Biol. Chem. 2005, 280, 11289-11294. [CrossRef] [PubMed]

18. Wang, Y.; Spellman, M.W. Purification and characterization of a GDP-fucose: Polypeptide fucosyltransferase from Chinese hamster ovary cells. J. Biol. Chem. 1998, 273, 8112-8118. [CrossRef] [PubMed]

19. Rampal, R.; Luther, K.; Haltiwanger, R. Notch Signaling in Normal and Disease States: Possible Therapies Related to Glycosylation. Curr. Mol. Med. 2007, 7, 427-445. [CrossRef] [PubMed]

20. Jafar-Nejad, H.; Leonardi, J.; Fernandez-Valdivia, R. Role of glycans and glycosyltransferases in the regulation of Notch signaling. Glycobiology 2010, 20, 931-949. [CrossRef] [PubMed]

21. Artavanis-Tsakonas, S.; Muskavitch, M.A.T. Notch: The Past, the Present, and the Future. In Current Topics in Developmental Biology; Elsevier: Amsterdam, The Netherlands, 2010; Volume 92, pp. 1-29. ISBN 978-0-12-380914-8. 
22. Shi, S.; Stanley, P. Protein O-fucosyltransferase 1 is an essential component of Notch signaling pathways. Proc. Natl. Acad. Sci. USA 2003, 100, 5234-5239. [CrossRef] [PubMed]

23. Takeuchi, H.; Yu, H.; Hao, H.; Takeuchi, M.; Ito, A.; Li, H.; Haltiwanger, R.S. O-Glycosylation modulates the stability of epidermal growth factor-like repeats and thereby regulates Notch trafficking. J. Biol. Chem. 2017, 292, 15964-15973. [CrossRef] [PubMed]

24. Stahl, M.; Uemura, K.; Ge, C.; Shi, S.; Tashima, Y.; Stanley, P. Roles of Pofut1 and Fucose in Mammalian Notch Signaling. J. Biol. Chem. 2008, 283, 13638-13651. [CrossRef] [PubMed]

25. Weng, A.P. Activating Mutations of NOTCH1 in Human T Cell Acute Lymphoblastic Leukemia. Science 2004, 306, 269-271. [CrossRef] [PubMed]

26. Göthert, J.R.; Brake, R.L.; Smeets, M.; Dührsen, U.; Begley, C.G.; Izon, D.J. NOTCH1 pathway activation is an early hallmark of SCL T leukemogenesis. Blood 2007, 110, 3753-3762. [CrossRef] [PubMed]

27. Bolós, V.; Mira, E.; Martínez-Poveda, B.; Luxán, G.; Cañamero, M.; Martínez-A, C.; Mañes, S.; de la Pompa, J.L. Notch activation stimulates migration of breast cancer cells and promotes tumor growth. Breast Cancer Res. 2013, 15, R54. [CrossRef] [PubMed]

28. Hsu, K.-W.; Hsieh, R.-H.; Huang, K.-H.; Fen-Yau Li, A.; Chi, C.-W.; Wang, T.-Y.; Tseng, M.-J.; Wu, K.-J.; Yeh, T.-S. Activation of the Notch1/STAT3/Twist signaling axis promotes gastric cancer progression. Carcinogenesis 2012, 33, 1459-1467. [CrossRef] [PubMed]

29. Zhang, Y.; Li, B.; Ji, Z.-Z.; Zheng, P.-S. Notch1 regulates the growth of human colon cancers. Cancer 2010, 116, 5207-5218. [CrossRef] [PubMed]

30. Kroes, R.A.; Dawson, G.; Moskal, J.R. Focused microarray analysis of glyco-gene expression in human glioblastomas. J. Neurochem. 2007, 103, 14-24. [CrossRef] [PubMed]

31. Yokota, S.; Ogawara, K.; Kimura, R.; Shimizu, F.; Baba, T.; Minakawa, Y.; Higo, M.; Kasamatsu, A.; Endo-Sakamoto, Y.; Shiiba, M.; et al. Protein O-fucosyltransferase 1: A potential diagnostic marker and therapeutic target for human oral cancer. Int. J. Oncol. 2013, 43, 1864-1870. [CrossRef] [PubMed]

32. Ma, L.; Dong, P.; Liu, L.; Gao, Q.; Duan, M.; Zhang, S.; Chen, S.; Xue, R.; Wang, X. Overexpression of protein $O$-fucosyltransferase 1 accelerates hepatocellular carcinoma progression via the Notch signaling pathway. Biochem. Biophys. Res. Commun. 2016, 473, 503-510. [CrossRef] [PubMed]

33. Dong, S.; Wang, Z.; Huang, B.; Zhang, J.; Ge, Y.; Fan, Q.; Wang, Z. Bioinformatics insight into glycosyltransferase gene expression in gastric cancer: POFUT1 is a potential biomarker. Biochem. Biophys. Res. Commun. 2017, 483, 171-177. [CrossRef] [PubMed]

34. Kallioniemi, A.; Kallioniemi, O.; Sudar, D.; Rutovitz, D.; Gray, J.; Waldman, F.; Pinkel, D. Comparative genomic hybridization for molecular cytogenetic analysis of solid tumors. Science 1992, 258, 818-821. [CrossRef] [PubMed]

35. Kimura, Y.; Noguchi, T.; Kawahara, K.; Kashima, K.; Daa, T.; Yokoyama, S. Genetic alterations in 102 primary gastric cancers by comparative genomic hybridization: Gain of $20 \mathrm{q}$ and loss of $18 \mathrm{q}$ are associated with tumor progression. Mod. Pathol. 2004, 17, 1328-1337. [CrossRef] [PubMed]

36. MacKinnon, R.N.; Selan, C.; Wall, M.; Baker, E.; Nandurkar, H.; Campbell, L.J. The paradox of 20q11.21 amplification in a subset of cases of myeloid malignancy with chromosome 20 deletion. Genes Chromosom. Cancer 2010, 49, 998-1013. [CrossRef] [PubMed]

37. Postma, C.; Hermsen, M.; Coffa, J.; Baak, J.; Mueller, J.; Mueller, E.; Bethke, B.; Schouten, J.; Stolte, M.; Meijer, G. Chromosomal instability in flat adenomas and carcinomas of the colon. J. Pathol. 2005, 205, 514-521. [CrossRef] [PubMed]

38. Loo, L.W.M.; Tiirikainen, M.; Cheng, I.; Lum-Jones, A.; Seifried, A.; Church, J.M.; Gryfe, R.; Weisenberger, D.J.; Lindor, N.M.; Gallinger, S.; et al. Integrated analysis of genome-wide copy number alterations and gene expression in microsatellite stable, $\mathrm{CpG}$ island methylator phenotype-negative colon cancer. Genes Chromosom. Cancer 2013, 52, 450-466. [CrossRef] [PubMed]

39. Loriol, C.; Audfray, A.; Dupuy, F.; Germot, A.; Maftah, A. The two N-glycans present on bovine Pofut1 are differently involved in its solubility and activity. FEBS J. 2007, 274, 1202-1211. [CrossRef] [PubMed]

40. Schuster-Gossler, K.; Harris, B.; Johnson, K.R.; Serth, J.; Gossler, A. Notch signalling in the paraxial mesoderm is most sensitive to reduced Pofut1 levels during early mouse development. BMC Dev. Biol. 2009, 9, 6 . [CrossRef] [PubMed]

41. Munkley, J.; Elliott, D.J. Hallmarks of glycosylation in cancer. Oncotarget 2016, 7, 35478. [CrossRef] [PubMed] 
42. Takeuchi, H.; Haltiwanger, R.S. Role of glycosylation of Notch in development. Semin. Cell Dev. Biol. 2010, 21, 638-645. [CrossRef] [PubMed]

43. Wang, Y.; Lee, G.F.; Kelley, R.F.; Spellman, M.W. Identification of a GDP-L-fucose: Polypeptide fucosyltransferase and enzymatic addition of $O$-linked fucose to EGF domains. Glycobiology 1996, 6, 837-842. [CrossRef] [PubMed]

44. Schneider, M.; Al-Shareffi, E.; Haltiwanger, R.S. Biological functions of fucose in mammals. Glycobiology 2017, 27, 601-618. [CrossRef] [PubMed]

45. Wan, G.; Tian, L.; Yu, Y.; Li, F.; Wang, X.; Li, C.; Deng, S.; Yu, X.; Cai, X.; Zuo, Z.; et al. Overexpression of Pofut1 and activated Notch1 may be associated with poor prognosis in breast cancer. Biochem. Biophys. Res. Commun. 2017, 491, 104-111. [CrossRef] [PubMed]

46. Lefort, N.; Feyeux, M.; Bas, C.; Féraud, O.; Bennaceur-Griscelli, A.; Tachdjian, G.; Peschanski, M.; Perrier, A.L. Human embryonic stem cells reveal recurrent genomic instability at 20q11.21. Nat. Biotechnol. 2008, 26, 1364-1366. [CrossRef] [PubMed]

47. Birkenkamp-Demtroder, K. Differential gene expression in colon cancer of the caecum versus the sigmoid and rectosigmoid. Gut 2005, 54, 374-384. [CrossRef] [PubMed]

48. Frattini, M. Different Genetic Features Associated with Colon and Rectal Carcinogenesis. Clin. Cancer Res. 2004, 10, 4015-4021. [CrossRef] [PubMed]

49. Kawahara, R.; Granato, D.C.; Carnielli, C.M.; Cervigne, N.K.; Oliveria, C.E.; Martinez, C.A.R.; Yokoo, S.; Fonseca, F.P.; Lopes, M.; Santos-Silva, A.R.; et al. Agrin and Perlecan Mediate Tumorigenic Processes in Oral Squamous Cell Carcinoma. PLoS ONE 2014, 9, e115004. [CrossRef] [PubMed]

50. Hugen, N.; Brown, G.; Glynne-Jones, R.; de Wilt, J.H.W.; Nagtegaal, I.D. Advances in the care of patients with mucinous colorectal cancer. Nat. Rev. Clin. Oncol. 2016, 13, 361-369. [CrossRef] [PubMed]

51. Zou, J.; Li, P.; Lu, F.; Liu, N.; Dai, J.; Ye, J.; Qu, X.; Sun, X.; Ma, D.; Park, J.; et al. Notch1 is required for hypoxia-induced proliferation, invasion and chemoresistance of T-cell acute lymphoblastic leukemia cells. J. Hematol. Oncol. 2013, 6, 3. [CrossRef] [PubMed]

52. De Craene, B.; Berx, G. Regulatory networks defining EMT during cancer initiation and progression. Nat. Rev. Cancer 2013, 13, 97-110. [CrossRef] [PubMed]

53. Gao, F.; Zhang, Y.; Wang, S.; Liu, Y.; Zheng, L.; Yang, J.; Huang, W.; Ye, Y.; Luo, W.; Xiao, D. Hes1 is involved in the self-renewal and tumourigenicity of stem-like cancer cells in colon cancer. Sci. Rep. 2015, 4, 3963. [CrossRef] [PubMed]

54. Ahadi, M.; Andrici, J.; Sioson, L.; Sheen, A.; Clarkson, A.; Gill, A.J. Loss of Hes1 expression is associated with poor prognosis in colorectal adenocarcinoma. Hum. Pathol. 2016, 57, 91-97. [CrossRef] [PubMed]

55. Reedjik, M.; Odorcic, S.; Zhang, H.; Chetty, R.; Tennert, C.; Dickson, B.C.; Lockwood, G.; Gallinger, S.; Egan, S.E. Activation of Notch signaling in human colon adenocarcinoma. Int. J. Oncol. 1992. [CrossRef]

56. Maier, M.M.; Gessler, M. Comparative Analysis of the Human and Mouse Hey1 Promoter: Hey Genes Are New Notch Target Genes. Biochem. Biophys. Res. Commun. 2000, 275, 652-660. [CrossRef] [PubMed]

57. Jarriault, S.; Brou, C.; Logeat, F.; Schroeter, E.H.; Kopan, R.; Israel, A. Signalling downstream of activated mammalian Notch. Nature 1995, 377, 355-358. [CrossRef] [PubMed]

58. Candy, P.A.; Phillips, M.R.; Redfern, A.D.; Colley, S.M.; Davidson, J.A.; Stuart, L.M.; Wood, B.A.; Zeps, N.; Leedman, P.J. Notch-induced transcription factors are predictive of survival and 5-fluorouracil response in colorectal cancer patients. Br. J. Cancer 2013, 109, 1023-1030. [CrossRef] [PubMed]

59. Hulleman, E.; Quarto, M.; Vernell, R.; Masserdotti, G.; Colli, E.; Kros, J.M.; Levi, D.; Gaetani, P.; Tunici, P.; Finocchiaro, G.; et al. A role for the transcription factor HEY1 in glioblastoma. J. Cell. Mol. Med. 2008, 13, 136-146. [CrossRef] [PubMed]

60. Kakuda, S.; Haltiwanger, R.S. Deciphering the Fringe-Mediated Notch Code: Identification of Activating and Inhibiting Sites Allowing Discrimination between Ligands. Dev. Cell 2017, 40, 193-201. [CrossRef] [PubMed]

61. Okajima, T.; Xu, A.; Lei, L.; Irvine, K.D. Chaperone Activity of Protein O-fucosyltransferase 1 Promotes Notch Receptor Folding. Science 2005, 307, 1599-1603. [CrossRef] [PubMed]

62. Ajima, R.; Suzuki, E.; Saga, Y. Pofut1 point-mutations that disrupt $O$-fucosyltransferase activity destabilize the protein and abolish Notch1 signaling during mouse somitogenesis. PLoS ONE 2017, 12, e0187248. [CrossRef] [PubMed] 
63. Bernardo, B.C.; Gao, X.-M.; Winbanks, C.E.; Boey, E.J.H.; Tham, Y.K.; Kiriazis, H.; Gregorevic, P.; Obad, S.; Kauppinen, S.; Du, X.-J.; et al. Therapeutic inhibition of the miR-34 family attenuates pathological cardiac remodeling and improves heart function. Proc. Natl. Acad. Sci. USA 2012, 109, 17615-17620. [CrossRef] [PubMed]

64. Hammer, Ø.; Harper, D.A.T.; Ryan, P.D. PAST: Paleontological statistics software package for education and data analysis. Palaeontol. Electron. 2001, 4, 9.

65. Livak, K.J.; Schmittgen, T.D. Analysis of Relative Gene Expression Data Using Real-Time Quantitative PCR and the $2^{-\triangle \triangle C T}$ Method. Methods 2001, 25, 402-408. [CrossRef] [PubMed]

(c) (C) 2018 by the authors. Licensee MDPI, Basel, Switzerland. This article is an open access article distributed under the terms and conditions of the Creative Commons Attribution (CC BY) license (http://creativecommons.org/licenses/by/4.0/). 